\title{
Underlying Factors Explaining Physical Behaviors among Office Workers-An Exploratory Analysis
}

\author{
Viktoria Wahlström ${ }^{1, *} \mathbb{C}$, David Olsson ${ }^{1}$, Fredrik Öhberg ${ }^{2}{ }^{(\mathbb{C}}$, Tommy Olsson ${ }^{1}$ (D) \\ and Lisbeth Slunga Järvholm ${ }^{1}$ \\ 1 Department of Public Health and Clinical Medicine, Umeå University, 90187 Umeå, Sweden; \\ david.olsson@umu.se (D.O.); tommy.g.olsson@umu.se (T.O.); lisbeth.slunga-jarvholm@umu.se (L.S.J.) \\ Department of Radiation Sciences, Umeå University, 90187 Umeå, Sweden; fredrik.ohberg@umu.se \\ * Correspondence: viktoria.wahlstrom@umu.se
}

Received: 6 October 2020; Accepted: 4 December 2020; Published: 8 December 2020

\begin{abstract}
Studies using technical measurements of physical behavior show wide interindividual variations. This study aimed to explore underlying factors related to sitting, standing and walking among office workers. Cross-sectional data for background characteristics, work-related variables, and device-based measures for sitting, standing and walking were collected among office workers in either a cell office or a flex office with activity-based work. Data were analyzed by Factor Analysis of Mixed Data (FAMD) and multiple robust linear regression. The FAMD resulted in the combination of underlying factors describing six character types. The (1) harmonic and healthy, (2) disabled with poor health, (3) manager that spend a lot of time in meetings and has very high workload, (4) engaged with high workload, (5) employee with creative and computer intense work, with high workload and, (6) employee with high BMI with creative and collaborative work. Regression analysis showed that the character type that was "engaged with high workload" sat more and stood less, while the character type with "high BMI and with creative and collaborative work" sat less. The results suggest that physical behavior among office workers is influenced by a complex combination of factors, which should be taken into account in the evaluation of future studies of larger cohorts.
\end{abstract}

Keywords: technical measurements; occupational health; office design; sedentary behavior; variance; workplace

\section{Introduction}

Due to the technical developments in society, the percentage of sedentary occupations has increased during the last 50 years [1]. Notably, office workers could spend up to three-quarters of their worktime seated [2-5] and excessive sitting may increase the risk of obesity, heart disease and premature death [6-8]. There is therefore a need for intervention studies aiming to change physical behaviors towards less sitting and more physical activity, such as standing and walking in this workgroup [9].

In office settings, many factors could influence patterns for physical behaviors. Qualitative studies have identified barriers and facilitators for decreasing sitting and increasing standing and walking in office settings. Social and cultural norms, leadership, work tasks, workload and musculoskeletal disorders have been described to impact physical behaviors at work [10-13]. Environmental factors like building and interior design have also been described as important for physical behaviors [13,14]. Thus, interventions to decrease sitting and increase standing and walking in offices are suggested to target environmental, organizational, group and individual levels $[9,15,16]$. Intervention studies in office settings have shown promising results regarding the possibility to reduce time in sitting and increase standing $[2,15]$. Sedentary behavior (SB) is defined as any waking behavior with an energy expenditure $\leq 1.5$ metabolic equivalents, in a lying, reclining or sitting posture [17]. Studies using 
technical measurements of SB and physical activity have shown wide standard deviations indicating large interindividual variations $[13,18]$, but the putative underlying factors for these variations are not yet fully explored $[5,19,20]$.

An exploratory study by Hadgraft et al. [19] using technical measurements of sitting, standing and walking among office workers showed a variation in sitting time between worksites. The study also shows that employees with more than five years of organizational tenure spent more time in total and prolonged sitting (>30 min), compared to those employed for 3-5 years. Notably, subjects with a high body mass index (BMI) (obese) spent less time in total and prolonged sitting time compared to normal-weight individuals. Another study examined whether the social-cognitive constructs, like knowledge and self-efficacy barriers, mediated intervention effects of a multicomponent intervention and found that variation in sitting reduction was only to a small extent explained by perceived behavioral control and individual self-efficacy barriers [21]. Sugiyama et al. [22] found that employees at worksites with mainly phone-based work or with mixed work tasks sat more compared to employees at worksites with non-phone-based work.

It is proposed that the office design could influence physical behaviors among office workers [23]. In recent years, flex offices with activity-based work (ABW) have increased in popularity $[24,25]$. Flex offices provide different workspaces for the employees. Workstations in landscape areas are complemented with support areas: cell offices for secluded work, meeting rooms in different sizes, lounges and break spaces. Employees do not have personal workstations and depending on the current work task, they are expected to choose a suitable space for the work task at hand [26].

As described, several factors might putatively influence physical behaviors in office settings, however, only a few studies have explored factors for these behaviors in office settings by using technical measurements of physical behaviors combined with a broad range of possible explaining factors [20]. These variations should be further explored in order to improve the efficacy, and evaluation of future workplace interventions focusing on decreasing sitting in office settings. The aim of the current study was to explore the underlying factors related to sitting, standing and walking behaviors among office workers in two different office types.

\section{Materials and Methods}

\subsection{Design, Recruitment and Participants}

We previously presented results from a multicomponent intervention study among office workers who relocated to different office types; one group to a cell office and the other to a flex office with ABW [27]. In short, results showed that employees sat for about $50 \%$ and stood for about $40 \%$ of the time at work in both groups already at baseline, which is lower levels of sitting and higher levels of standing compared to other studies. No changes in sitting or standing time were observed after the intervention. However, the time spent walking increased in the group moving to the flex office. Similar to other studies, our data also showed wide interindividual variations [19,27].

Participants were recruited among office workers in a public administrative workplace in northern Sweden. The Active Office Design (AOD) study had a longitudinal design with follow-up of employees in two groups, where one group moved to a new flex office, and the other to a new cell office [27]. Employees in departments for economy, human resources, urban planning, education, and politicians, relocated to the flex office with ABW, while the welfare office including social workers moved to a building with a cell office design. We collected repeated technical measurements for sitting, standing and walking, questionnaire data on lifestyle and health, detailed information on work tasks, and work-related psychosocial factors. Detailed information about work tasks was collected at 18 months after relocation. These assessments provided novel opportunities to perform exploratory analyses of underlying factors for physical behaviors among office workers. To be included for technical measurements of physical behaviors employees should be between 18-63 years, work $75 \%$ or more, and spend more than $60 \%$ of work time in the office. The participants were 
recruited following a computer-generated list, based on all employees included in the office relocation. The randomly selected employees were contacted via an e-mail invitation followed by a phone interview. Originally 86 participants were recruited for the study. At follow-up at 18 months after relocation, there were 59 participants left in the study. In the current study, we performed a secondary analysis, using cross-sectional data collected at 18 months after relocation. We finally included 53 participants with complete data. The reasons for drop-out were related to parental leave, sick leave, retirement or relocation to another office. More details on the study design, recruitment and reasons for drop-out are described elsewhere [27]. Employees were informed that participation was voluntary and that they could withdraw participation at any time according to the Declaration of Helsinki. All participants signed informed consent prior to participation. Ethical approval was granted by the Regional Ethical Review Committee in Umeå, SE (No: 2014/226-31).

\subsection{Setting}

In both offices, all workstations had sit-stand tables and adjustable chairs. The flex office was equipped with sit-stand tables in some meeting rooms, and both sitting and standing tables in the break spaces. Waste-paper bins and printer rooms were centrally placed on each floor, and 16 treadmills were placed in the flex office. In the cell office, each floor had corridors with personal cell offices along the outer walls. In the middle, there were shared surfaces like meeting rooms, break spaces and archives.

Both before and during the study, the studied organization, including both the cell office and the flex office group had an ongoing systematic health-promoting program, including, i.e., subsidized gym fees, annual step-count competitions, and bicycles were available for transport to meetings outside the office. The organization had a policy that employees could exercise for one hour a week during working hours (common in Sweden). For both office groups, a multicomponent PA promoting program, including environmental, organizational-, group- and individual-level components was implemented prior to the follow-up at 18 months. The intervention program has been described in detail elsewhere [27].

\subsection{Measures}

\subsubsection{Background Characteristics and Personal Health}

In the questionnaire, participants reported age, gender, office type, and employment rate. Self-rated general health was assessed by a question from the SF-36 Short-form Health Survey which has shown strong reliability and validity [28]. Musculoskeletal symptoms from different body regions were reported by five items on a five-graded scale from never to always [29]. Mental disorders like stress and concentration difficulties were reported by two items on a five-graded scale from never to always [29]. Quality of sleep was reported on a five-graded scale between "very good" to "very bad" using the question "How do you perceive your sleep overall?" from the Karolinska Sleep Questionnaire [30]. Exercise habits were reported using the question "How often have you worked out or exercised in training clothes during the last 3 months, to improve your fitness and/or your wellbeing?" and answers were provided on a five-graded scale from never to $>3$ times per week [31]. Measurements of height and weight were performed at the workplace 18 months after relocation. Participants wore underwear, and standardized methods were used [32]. Body mass index (BMI) was calculated by using the body height, measured to the nearest $0.1 \mathrm{~cm}$ with a wall-mounted stadiometer (Hyssna 4146, Hyssna Measuring Equipment AB, Hyssna, Sweden), and body weight measured the nearest $0.1 \mathrm{~kg}$ using a calibrated electronic digital scale (Tanita BWB-800 MA; Umedico AB, Rosersberg, Sweden).

\subsubsection{Work-Related Variables}

Measures for both work tasks and psychosocial work situations were assessed in the questionnaires. Participants reported the total number of work hours per week and the number of hours per week spent in both small ( $2-3$ persons) and large meetings ( $>3$ persons). Based on this, meeting participation 
was calculated to a relative value per week. The number of meetings outside the office within walking or cycling distance was reported on a six graded scale from "never" to "daily". Hours of computer-based work per day were reported on a four graded scale (from $0-1 \mathrm{~h}$ to $6-8 \mathrm{~h}$ per day). Work requirements, like the need to discuss with colleagues, to be creative or fully concentrated, were assessed by eight items on a five-graded scale from "never" to "always". This instrument has not been validated but was developed by the researcher Helena Jahncke to further understand the content of work tasks related to office design. The instrument is based on results from laboratory studies, identifying work tasks and processes affected by noise in open landscape offices [33,34].

To measure experiences of work and the workplace we used the Work Experience Measurement Scale (WEMS) [35], which includes 32 statements grouped into six dimensions; (1) Supportive working conditions, (2) Internal work experience, (3) Autonomy, (4) Time pressure, (5) Management and (6) Reorganization. Each statement was assessed on a six-graded scale from "Do not agree at all" to "Totally agree". WEMS has been designed to measure specific work-related aspects and salutogenic work factors. It is developed from theories related to a sense of coherence, demand/control/support, flow, and effort/reward.

For assessments of physical, mental and social well-being we used the Salutogenic Health Indicator Scale (SHIS) [36]. Twelve statements were assessed on a six-graded scale. An example of a statement could be, "During the last four weeks I have: (1) felt full of ideas and been creative, to (6) had a lack of ideas and creativity. Results from the 12 statements were combined into two dimensions; "Intrapersonal traits" (IPK) capturing perceived personal health state and the "interactive function" (IAF) measuring coping and interaction on requirements related to the working environment. Both for SHIS and WEMS results from all questions were weighted as a total index. The result was then standardized to a scale from 0 to 100 . A high value indicates a high degree of positive experiences from work (WEMS) and perceived health (SHIS) [36]. Cognitive stress was measured using four questions from the second version of the Copenhagen Psychosocial Questionnaire (COPSOQ II), where problems with the ability to concentrate, make decisions, remember things or solve problems, was reported on a five-graded scale from never to always. In the analysis, the mean value of these four items was used [37]. The workload was assessed by the question "What are your thoughts on your workload?" and was reported on a six-graded scale from "too low" to "so heavy that I am bordering on exhaustion".

\subsubsection{Technical Measurements of Physical Behavior—Sitting, Standing and Walking}

Technical measurements of physical behaviors were performed over seven consecutive days. Participants wore ActivPAL3 or the ActivPAL3 micro (PAL Technologies Limited, Glasgow, Scotland; default settings) on the right thigh for $24 \mathrm{~h}$ per day for one week. ActivPAL provides valid, reliable, and sensitive measurements for time spent sitting, standing and walking [38,39]. Data were processed using a custom Excel macro (HSC PAL analysis software v2.19s, developed by researcher Philippa Dall and Malcolm Granat, Glasgow, UK). By using a logbook during the week of measurement, participants noted what time they got up, went to bed, started and finished work, whether it was a work or non-workday, periods of non-wear time or adverse events related to the measurements. The logbook was used to distinguish between work time and total awake time on workdays. In this study, we used data from work time only. To be eligible for analysis, the measurement period had to include at least 3 workdays and $\geq 4 \mathrm{~h}$ of work time was required [40]. The activity outcomes were standardized to an $8 \mathrm{~h}$ workday. Time spent in sitting $>30 \mathrm{~min}$ bouts was defined as the time in prolonged sitting.

\subsection{Statistical Analysis and Process for Result Interpretation}

Before any analyses, all scales in the questionnaire were adapted so that high numbers corresponded to a high value. All continuous variables were standardized by transforming to a mean value of zero and a standard deviation of one.

We combined Factor Analysis of Mixed Data (FAMD) with multiple linear regression. FAMD is a generalized principal component method that allows for both categorical and continuous data. 
Just like principal component analysis, FAMD aims to reduce the number of factors in the dataset while retaining as much of the variation as possible from the original dataset [41], and is a useful multivariate data analysis method to identify patterns within variables. The factors will contain combinations of variables, and the factors emerging will be uncorrelated. This means that we will not introduce bias in a regression model, or inflate the standard error estimates by including the factors as separate explanatory variables. Thus, allowing us to simultaneously assess any association between our explanatory variables, physical behaviors and office type without the loss of statistical power. In the first step, we performed a FAMD on the background characteristics, personal health and work-related variables to reduce the number of factors in the dataset. Each factor contained unique combinations of personal health (i.e., self-reported health, sleep, pain), factors related to work tasks (i.e., time spent in meetings, amount of computer work and work requirements), and the psychosocial work situation (data from WEMS, SHIS, COPSOQC). We used a scree plot to determine the number of factors that should be kept for the analyses, based on where the Scree plot leveled out (Figure 1). The combinations of variables in each factor were interpreted by two of the authors, first separately and then together. The interpretation was based on the explanatory variables that fell out significant in each factor. The higher degree of explanation of variation a variable had, the more impact on the interpretation. The combination of exploratory variables emerged from the FAMD and the factors could be described as the base for "animated" employees. The explaining variables were lastly verbally condensed to describe character types.

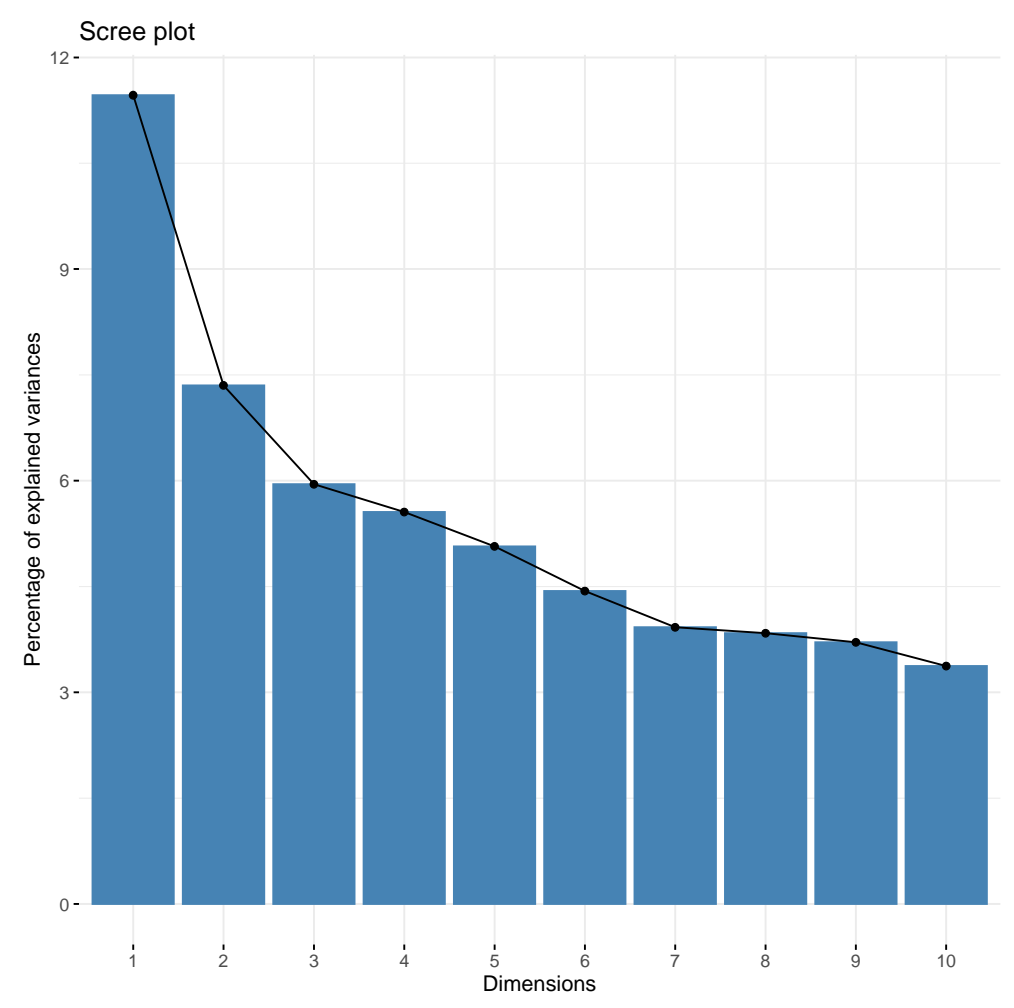

Figure 1. The Scree plot of the factors. The first six factors were further analyzed.

In the second step, we performed multiple robust linear regression analyses to explore associations between the character types (factors), the ActivPAL data on sitting, standing and walking and office type. In the linear regression analyses, we decided to report all estimated associations between character types (factors) and data for sitting, standing and walking per interquartile range increase (IQR), where IQR is defined as the difference between the 75th and 25th percentile. We used an interquartile range instead of a unit increase, since a unit increase in any given character type does not have a specific meaning, meanwhile, an interquartile range increase at least gives the magnitude of 
the effect for a given character type. The statistical significance was determined by $95 \%$ confidence intervals. The FAMD analysis was performed using the "FactoMineR" and "factoextra" packages and the multiple robust linear regression models were fitted using the "MASS" package in R computing software, version 3.5.2 (R Foundation for Statistical Computing, Vienna, Austria). For descriptive statistics of sample characteristics, we used SPSS software v.24 (IBM Corp, Armonk, NY, USA).

\section{Results}

\subsection{Participant Characteristics}

The characteristics of participants are presented in Table 1 . Approximately $60 \%$ of the participants exercised $\geq 2$ times per week and $40 \%$ exercised once a week or less. On average participants spent $53 \%$ of their worktime sitting, $38 \%$ standing and $9 \%$ walking.

Table 1. Characteristics of participants, $n=53$.

\begin{tabular}{|c|c|c|}
\hline & Mean (SD) & $n(\%)$ \\
\hline \multicolumn{3}{|l|}{ Background and lifestyle variables } \\
\hline Female & & $44(83)$ \\
\hline Age & $52.3(9.4)$ & \\
\hline BMI & $26.2(3.7)$ & \\
\hline \multicolumn{3}{|l|}{ Physical exercise } \\
\hline No exercise & & $6(11)$ \\
\hline Occasionally_not regular & & $9(17)$ \\
\hline 1 time per week & & $6(11)$ \\
\hline 2-3 times per week & & $23(44)$ \\
\hline$>3$ times per week & & $9(17)$ \\
\hline Health variables & & \\
\hline \multicolumn{3}{|l|}{ Self-rated general health } \\
\hline Very good or excellent & & $29(55)$ \\
\hline Good & & 19 (36) \\
\hline Fair or bad & & $5(9)$ \\
\hline \multicolumn{3}{|l|}{ Sleep disorders a } \\
\hline Never or seldom & & $28(54)$ \\
\hline Sometimes & & $16(31)$ \\
\hline Often or always & & $8(15)$ \\
\hline \multicolumn{3}{|l|}{ Discomfort from neck and shoulders $b$} \\
\hline Never or seldom & & $18(35)$ \\
\hline Sometimes & & $16(31)$ \\
\hline Often or always & & $17(33)$ \\
\hline \multicolumn{3}{|l|}{ Work-related variables } \\
\hline Managerial position & & $8(15)$ \\
\hline \multicolumn{3}{|l|}{ Computer work per day } \\
\hline $0-2 \mathrm{~h}$ & & $0(0)$ \\
\hline $2-4 \mathrm{~h}$ & & $5(9)$ \\
\hline $4-6 \mathrm{~h}$ & & $20(37)$ \\
\hline $6-8 \mathrm{~h}$ & & $28(53)$ \\
\hline \multicolumn{3}{|l|}{ Workload a } \\
\hline Too low & & $0(0)$ \\
\hline Adequate, never bothersome & & $2(4)$ \\
\hline Sometimes bothersome & & $27(52)$ \\
\hline Somewhat bothersome & & $9(17)$ \\
\hline Often bothersome & & $10(19)$ \\
\hline $\begin{array}{l}\text { So heavy that I am bordering on } \\
\text { exhaustion }\end{array}$ & & $4(8)$ \\
\hline \multicolumn{3}{|l|}{ Office type } \\
\hline Flex office & & $28(53)$ \\
\hline Cell office & & $25(47)$ \\
\hline
\end{tabular}


Table 1. Cont.

\begin{tabular}{|c|c|c|}
\hline & Mean (SD) & $n(\%)$ \\
\hline Activity outcomes per 8-h workday & & \\
\hline Total sitting time per day, $\%$ & $53.1(17.0)$ & \\
\hline Time spent in prolonged sitting per day, \% & $22.7(12.1)$ & \\
\hline Total standing time per day, $\%$ & 37.5 (16.7) & \\
\hline Total walking time per day, $\%$ & $9.4(3.2)$ & \\
\hline
\end{tabular}

\subsection{Factor Analysis of Mixed Data}

For each factor, the FAMD resulted in a complex combination of factors. These factors together explained $31 \%$ of the total variance in the data. The combination of significant variables within the factors resulted in a description of six character types that were named (1) harmonic and healthy, (2) disabled with poor health, (3) manager that spend a lot of time in meetings and has very high workload, (4) engaged with high workload, (5) creative and computer intense work, with high workload, and, (6) had high BMI and creative and collaborative work. The list of the significant variables and the characters types is presented in Table 2.

\subsection{Regression Analysis}

In the second step, we explored how the different character types and office types related to activity outcomes for sitting, standing, walking (Table 3). The character type "engaged with high workload", stood less and spent more time in both total and prolonged sitting, when in the fourth quartile compared to the first quartile. The character type with "a high BMI with creative and collaborative work" sat $34 \mathrm{~min}$ less and stood $30 \mathrm{~min}$ more, where the sitting time was significant (Table 3). The "harmonic and healthy" seemed to sit more and stand less, but this was not significant. Office type did not affect the level of sitting, standing or walking at work. The variables included in the regression models explained $20.8 \%$ of the variation in standing time and $12.8 \%$ of walking time variation. For sitting and prolonged sitting, $22.3 \%$ and $19.3 \%$ of the variation was explained. 
Table 2. Presentation of the character types, based on variables of influence from the factor analysis of mixed data. Covariates and factors for each character type are presented in descending order, based on $\mathrm{r} 2$.

\begin{tabular}{|c|c|c|c|c|c|}
\hline Character Type & Condensed Characteristics & $\begin{array}{l}\text { Significant Variables of Influence, } \\
\text { Presented in Descending Order }\end{array}$ & Level & $\begin{array}{l}\text { Correlation }(\mathbf{r}), \\
\text { Scale Data }\end{array}$ & $\begin{array}{l}\text { Estimated } \mathbf{r}^{2}, \\
\text { Ordinal Data }\end{array}$ \\
\hline \multirow{12}{*}{$\begin{array}{l}\text { "The harmonic and } \\
\text { healthy employee" }\end{array}$} & \multirow{12}{*}{$\begin{array}{l}\text { The harmonic employee with good } \\
\text { health and high wellbeing. No problems } \\
\text { with stress, sleep, pain or concentration. }\end{array}$} & Interpersonal traits ${ }^{a}$ & & 0.78 & \\
\hline & & Interactive function ${ }^{a}$ & & 0.77 & \\
\hline & & Cognitive stress & & -0.72 & \\
\hline & & Symptoms of stress & Seldom or never & & 0.47 \\
\hline & & Concentration disorders & Seldom or never & & 0.44 \\
\hline & & Sleep quality & Very good & & 0.42 \\
\hline & & Concentration demands & Medium & & 0.40 \\
\hline & & Exhaustion disorder & No & & 0.37 \\
\hline & & Discomfort in neck and shoulders & Seldom & & 0.35 \\
\hline & & Need to be fully concentrated at work & Seldom & & 0.35 \\
\hline & & Perceived support at work & & 0.57 & \\
\hline & & Self-reported health & Very good & & 0.32 \\
\hline \multirow{12}{*}{$\begin{array}{l}\text { "The disabled employee } \\
\text { with poor health" }\end{array}$} & \multirow{12}{*}{$\begin{array}{l}\text { The disabled employee with poor health, } \\
\text { musculoskeletal disorders, high BMI, } \\
\text { concentration difficulties and high stress } \\
\text { levels. Work requires high creativity, } \\
\text { a need to learn new things and to discuss } \\
\text { with colleagues. }\end{array}$} & Discomfort in hip, knee or feet & Always & & 0.60 \\
\hline & & Discomfort in back & Always & & 0.58 \\
\hline & & Discomfort in neck and shoulders & Always & & 0.39 \\
\hline & & BMI & & 0.62 & \\
\hline & & Weight & & 0.57 & \\
\hline & & Concentration disorders & Often or always & & 0.26 \\
\hline & & Need to learn new things at work & Sometimes & & 0.24 \\
\hline & & Self-reported health & Fair or bad & & 0.23 \\
\hline & & Need to be creative at work & Often & & 0.23 \\
\hline & & Symptoms of stress & Always & & 0.22 \\
\hline & & Need to remember things at work & Sometimes & & 0.21 \\
\hline & & Need to discuss with colleagues & Sometimes & & 0.17 \\
\hline
\end{tabular}


Table 2. Cont.

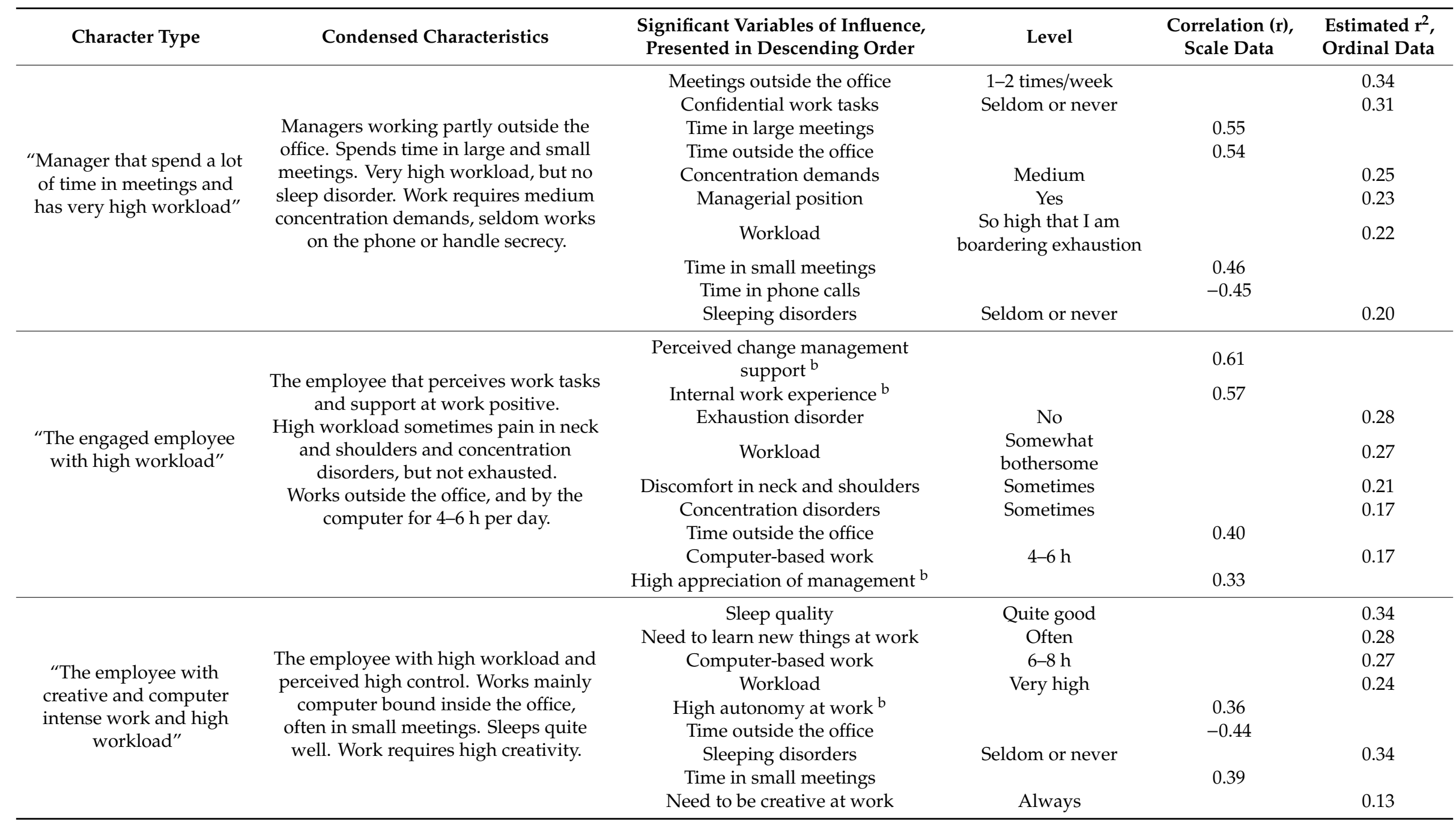


Table 2. Cont

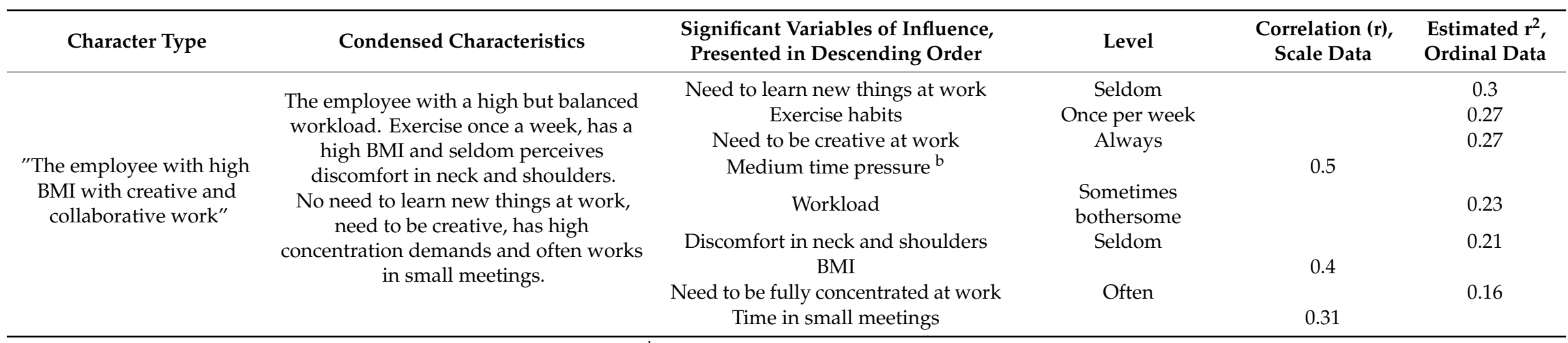

${ }^{a}$ Salutogenic Health Indicator Scale, high value indicates good health, ${ }^{\mathrm{b}}$ Work Experience Measurement Scale, high value indicates a positive experience of working conditions. 
Table 3. Results from robust regression analysis, showing the impact of character types and office type on activity outcomes. The effects of character types are reported per interquartile range (IQR) increase. IQR is defined as the difference between the 75th and 25 th percentile of the factor scale. Statistically significant outcomes are marked in bold.

\begin{tabular}{|c|c|c|}
\hline Activity Outcome and Character Name & Minutes/Day & $95 \% \mathrm{CI}$ \\
\hline \multicolumn{3}{|l|}{ Total sitting time } \\
\hline Flex Office (reference cell office) & -17 & $(-87,52)$ \\
\hline "The harmonic and healthy employee" & 39 & $(-5,83)$ \\
\hline “The disabled employee with poor health" & -17 & $(-34,1)$ \\
\hline "Manager that spend a lot of time in meetings and has very high workload" & -9 & $(-37,19)$ \\
\hline "The engaged employee with high workload" & 32 & $(4,60)$ \\
\hline "The employee with creative and computer intense work and high workload" & 16 & $(-14,45)$ \\
\hline "The employee with high BMI with creative and collaborative work" & -34 & $(-68,-1)$ \\
\hline \multicolumn{3}{|l|}{ Prolonged sitting time } \\
\hline Flex Office (reference cell office) & -28 & $(-78,22)$ \\
\hline "The harmonic and healthy employee" & 14 & $(-18,45)$ \\
\hline "The disabled employee with poor health" & -10 & $(-22,2)$ \\
\hline "Manager that spend a lot of time in meetings and has very high workload" & 18 & $(-2,38)$ \\
\hline "The engaged employee with high workload" & 28 & $(8,48)$ \\
\hline "The employee with creative and computer intense work and high workload" & 6 & $(-15,26)$ \\
\hline "The employee with high BMI with creative and collaborative work" & -22 & $(-46,2)$ \\
\hline \multicolumn{3}{|l|}{ Standing time } \\
\hline Flex Office (reference cell office) & 16 & $(-57,89)$ \\
\hline "The harmonic and healthy employee" & -45 & $(-90,1)$ \\
\hline “The disabled employee with poor health" & 15 & $(-3,33)$ \\
\hline "Manager that spend a lot of time in meetings and has very high workload" & 6 & $(-23,36)$ \\
\hline "The engaged employee with high workload" & -29 & $(-58,0)$ \\
\hline "The employee with creative and computer intense work and high workload" & -12 & $(-42,18)$ \\
\hline "The employee with high BMI with creative and collaborative work" & 30 & $(-5,65)$ \\
\hline \multicolumn{3}{|l|}{ Walking time } \\
\hline Flex Office (reference cell office) & 0 & $(-10,11)$ \\
\hline "The harmonic and healthy employee" & 6 & $(-1,12)$ \\
\hline “The disabled employee with poor health" & 0 & $(-2,3)$ \\
\hline "Manager that spend a lot of time in meetings and has very high workload" & 2 & $(-2,7)$ \\
\hline "The engaged employee with high workload" & -3 & $(-7,2)$ \\
\hline "The employee with creative and computer intense work and high workload" & -3 & $(-8,1)$ \\
\hline "The employee with high BMI with creative and collaborative work" & 4 & $(-1,9)$ \\
\hline
\end{tabular}

\section{Discussion}

The aim of this study was to explore the underlying factors related to sitting, standing and walking among office workers in two office types by using device-based data on physical behaviors, and a broad range of possible explaining factors. Our results revealed that a complex combination of factors related to personal health, work tasks and psychosocial work situation influenced patterns for sitting and standing at work. These results suggest that office workers are a heterogeneous group in these respects, even if they work within the same organization.

We found that the "engaged employee with high workload" spent more time in total and prolonged sitting. Exploring data from a previous cluster-randomized trial, Hadgraft et al. [19] found large differences in sitting time between worksites. When analyzing data from the same trial, Sugimaya et al. [22] found that the level of task variation differed between teams, and those with a high degree of phone-based work spent more time sitting than teams with other tasks. Our results suggest that both work engagement, workload and type of work tasks seem to influence total sitting time and the way sitting time is accumulated at work.

The character types that were highly "harmonic and healthy" had a tendency to sit more and stand less, although not statistically significant. To our knowledge, there are no previous studies with similar exploratory results, although a qualitative study by Flint et al. [42] reported that regular 
exercisers or those with a young family, which could be presumed to have good health, were less motivated to reduce their sedentary time at work. In line with these results, Nooijen et al. [43] found that a higher proportion of young workers reported that they thought standing was uncomfortable and tiring, and were less motivated to stand at work, and a higher proportion of men reported regular exercise as a barrier to standing at work. The results from Flint et al. and Nooijen et al. [42,43] might indicate that individuals with good health might be less worried about the health risks of excessive sitting, and therefore tend to sit more at work, which is in line with our results.

In our study, the character type with "high BMI and creative and collaborative work" sat less. Hadgraft et al. [19] found that employees with high BMI sat less compared to those with a normal BMI. The "manager that spend a lot of time in meetings and has very high workload" did not sit or walk more than other character types, even though they spent more time in meetings and more time outside the office. This might be due to managers' high autonomy in their performance of work tasks.

In a study investigating health beliefs and attitudes among office workers, Sudholz et al. [44] found that employees and employers associated occupational sitting more with musculoskeletal disorders and performance-related concerns rather than long-term health effects. Intervention studies where participants have decreased their sitting and increased their standing time have shown improvements in musculoskeletal disorders [45-47]. In our study "the disabled employee with poor health" did not seem to sit more than other character types, and the average standing time was high during the whole study period [27]. This may indicate that interventions to reduce sitting and increase standing, successfully could reach out to individuals that would gain mostly with positive health effects. Individuals with musculoskeletal disorders might also choose to vary between sitting and standing to a greater extent to increase variation as a way to cope with their symptoms.

As the work tasks and the psychosocial work situation of office workers can vary a lot, the local context is of importance when developing interventions. Previous studies recommend multicomponent interventions, targeting both environmental-, organizational-, group-, and individual levels [23,48]. To be able to address specific barriers and enhance possibilities to decrease sitting and increase standing and walking in an organization, a recent study emphasizes the need for a participatory approach when designing interventions [16]. The participatory approach creates an opportunity to consider local contexts, like work tasks, the health-promoting culture and physical environment. The results of this study indicate that office workers have different physical behaviors depending on a complex combination of both health- and work-related factors. We recently published a study where the implementation process of the PA promoting program was evaluated using mixed methods [49]. The process evaluation was performed in the flex office group, representing $53 \%$ of the study population in the current study. The qualitative results showed that physical behaviors were contextual, influenced by many different factors and could vary substantially between individuals [49]. The results for the secondary analysis in the current study confirm the complex combination of underlying factors for physical behaviors among office workers. Based on our new results here presented, we would suggest that interventions might even need to be tailored on a group level within organizations, i.e., different departments, to be more realistic and specific, which might lead to improved effects.

A limitation of this study is the cross-sectional design which restricts the possibility to assess how different variables change over time. The relatively small sample size, with only a few men and managers, also lowers the generalizability of the results. The working hours, culture, norms and physical environment in offices could also differ between countries. In our study, the organization had a strong tradition to promote a healthy lifestyle and physical activity, and all workers already had sit-stand tables, which decrease the possibility to generalize our results to other office populations. Further, the data analyzed in this study were collected shortly after the implementation of a multicomponent PA promoting program, aiming to decrease sitting and increase standing and walking. Altogether, this suggests that the results should only with caution be generalized to other office populations. We previously presented results from the AOD Study that showed significant interaction effects in walking time and number of steps over time between employees working in the cell versus flex 
office [27]. In the current study, the office type did not seem to be related to behaviors for sitting, standing or walking, which might be caused by loss of power due to the cross-sectional design.

Strengths of this study include the technical measures for sitting, standing and walking, combined with a broad range of questionnaire data on background characteristics, personal health and work-related variables. This enables an increased understanding of the complexity of factors of importance for physical behaviors in office settings. The advantage of using a generalized principal component method before analyzing the outcomes is that the number of explanatory variables is reduced. This makes it feasible to explore the association between a wide range of putative explaining variables and the data on physical behaviors. However, this methodology complicates the interpretation of the regression analysis, as it is not obvious exactly what the resulting factors represent.

Even though the interpretation of our results should be carried out with caution, our results indicate that physical behaviors among office workers are associated with complex combinations of explanatory variables. This complexity suggests that many aspects are to be considered both when planning interventions and evaluating effects from this type of organizational interventions. In addition to detailed descriptions of the worksite culture and physical environment, also workload, health variables such as BMI, musculoskeletal disorders, amount of computer work, and specific work requirements could be possible mediators in an intervention. Therefore, data collection with a broad perspective on work factors is important in future studies.

\section{Conclusions}

We found that complex combinations of factors influence physical behaviors among office workers. The interindividual variation of time spent sitting, standing and walking were only partly explained by our multifactorial approach. More studies using technical measures for physical behaviors, combined with assessments of a broad range of possible underlying factors should be taken into account in the evaluation of future studies of larger cohorts.

Author Contributions: Conceptualization, V.W., D.O., F.Ö., T.O., and L.S.J.; Data curation, V.W. and D.O.; Formal analysis, V.W. and D.O.; Investigation, V.W. and L.S.J.; Methodology, V.W., D.O., F.Ö., T.O., and L.S.J.; Project administration, V.W. and L.S.J.; Supervision, L.S.J.; Writing—original draft, V.W.; Writing-review \& editing, D.O., F.Ö., T.O., and L.S.J. All authors participated substantially in data interpretation, commented on subsequent drafts, and approved the final version of the manuscript for publication. All authors have read and agreed to the published version of the manuscript.

Funding: This research was funded by AFA Insurance (grant number 140308), Umeå University and Västerbotten County Council.

Acknowledgments: We would like to acknowledge the funders to this study, AFA Insurance (grant number 140308), Umeå University and Västerbotten County Council. We want to thank the employees in the municipality of Örnsköldsvik for their participation during the study. We would also like to thank Philippa Dall and Malcolm Granat (Glasgow Caledonian University, UK) for letting us use the HSC PAL analysis software, and MD Helena Jahncke for letting us use the questions developed to assess work requirements. We would also like to thank the developers of the SHIS and WEMS questionnaires, who gave us permission to use them.

Conflicts of Interest: The authors declare no conflict of interest. Funders had no role or influence on study design, data collection, analysis, interpretation of the data or manuscript writing, nor the decision to publish the results.

\section{References}

1. Church, T.S.; Thomas, D.M.; Tudor-Locke, C.; Katzmarzyk, P.T.; Earnest, C.P.; Rodarte, R.Q.; Martin, C.K.; Blair, S.N.; Bouchard, C. Trends over 5 decades in U.S. occupation-related physical activity and their associations with obesity. PLoS ONE 2011, 6, e19657. [CrossRef] [PubMed]

2. Danquah, I.H.; Kloster, S.; Holtermann, A.; Aadahl, M.; Bauman, A.; Ersbøll, A.K.; Tolstrup, J.S. Take a Stand!-A multi-component intervention aimed at reducing sitting time among office workers-a cluster randomized trial. Int. J. Epidemiol. 2017, 46, 128-140. [CrossRef] [PubMed]

3. Hallman, D.M.; Mathiassen, S.E.; Jahncke, H. Sitting patterns after relocation to activity-based offices: A controlled study of a natural intervention. Prev. Med. 2018, 111, 384-390. [CrossRef] [PubMed] 
4. Parry, S.; Straker, L.; Gilson, N.D.; Smith, A.J. Participatory workplace interventions can reduce sedentary time for office workers-A randomised controlled trial. PLoS ONE 2013, 8. [CrossRef] [PubMed]

5. Smith, L.; Sawyer, A.; Gardner, B.; Seppala, K.; Ucci, M.; Marmot, A.; Lally, P.; Fisher, A. Occupational physical activity habits of UK office workers: Cross-sectional data from the active buildings study. Int. J. Environ. Res. Public Health 2018, 15, 1214. [CrossRef] [PubMed]

6. Biswas, A.; Oh, P.I.; Faulkner, G.E.; Bajaj, R.R.; Silver, M.A.; Mitchell, M.S.; Alter, D.A. Sedentary time and its association with risk for disease incidence, mortality, and hospitalization in adults a systematic review and meta-analysis. Ann. Intern. Med. 2015, 162, 123-132. [CrossRef] [PubMed]

7. Diaz, K.M.; Howard, V.J.; Hutto, B.; Colabianchi, N.; Vena, J.E.; Safford, M.M.; Blair, S.N.; Hooker, S.P. Patterns of sedentary behavior and mortality in U.S. middle-aged and older adults a national cohort study. Ann. Intern. Med. 2017, 167, 465-475. [CrossRef]

8. Fisman, E.I.; Steeves, J.A.; Zipunnikov, V.; Koster, A.; Berrigan, D.; Harris, T.; Murphy, R. Association between Objectively Measured Physical Activity and Mortality in NHANES. Med. Sci. Sport. Exerc. 2016, 48, 1303-1311. [CrossRef]

9. Owen, N.E. Al Too Much Sitting: The Population-Health Science of Sedentary Behavior. Ex. Sport. Sci. Revires 2010, 38, 105-113. [CrossRef]

10. De Cocker, K.; Veldeman, C.; De Bacquer, D.; Braeckman, L.; Owen, N.; Cardon, G.; De Bourdeaudhuij, I. Acceptability and feasibility of potential intervention strategies for influencing sedentary time at work: Focus group interviews in executives and employees. Int. J. Behav. Nutr. Phys. Act. 2015, 12, 1-11. [CrossRef]

11. Hadgraft, N.T.; Brakenridge, C.L.; Lamontagne, A.D.; Fjeldsoe, B.S.; Lynch, B.M.; Dunstan, D.W.; Owen, N.; Healy, G.N.; Lawler, S.P. Feasibility and acceptability of reducing workplace sitting time: A qualitative study with Australian office workers. BMC Public Health 2016, 16, 933. [CrossRef] [PubMed]

12. Sawyer, A.; Smith, L.; Ucci, M.; Jones, R.; Marmot, A.; Fisher, A. Perceived office environments and occupational physical activity in office-based workers. Occup. Med. (Chic. Ill.) 2017, 67, 260-267. [CrossRef] [PubMed]

13. Waters, C.N.; Ling, E.P.; Chu, A.H.Y.; Ng, S.H.X.; Chia, A.; Lim, Y.W.; Müller-Riemenschneider, F. Assessing and understanding sedentary behaviour in office-based working adults: A mixed-method approach. BMC Public Health 2016, 16, 360. [CrossRef] [PubMed]

14. Gilson, N.D.; Burton, N.W.; van Uffelen, J.G.Z.; Brown, W.J. Occupational sitting time: Employees' perceptions of health risks and intervention strategies. Health Promot. J. Aust. 2011. [CrossRef] [PubMed]

15. Hutcheson, A.K.; Piazza, A.J.; Knowlden, A.P. Work Site-Based Environmental Interventions to Reduce Sedentary Behavior: A Systematic Review. Am. J. Health Promot. 2018. [CrossRef] [PubMed]

16. Mackenzie, K.; Such, E.; Norman, P.; Goyder, E. The development, implementation and evaluation of interventions to reduce workplace sitting: A qualitative systematic review and evidence-based operational framework. BMC Public Health 2018, 18. [CrossRef]

17. Tremblay, M.S.; Aubert, S.; Barnes, J.D.; Saunders, T.J.; Carson, V.; Latimer-Cheung, A.E.; Chastin, S.F.M.; Altenburg, T.M.; Chinapaw, M.J.M.; Aminian, S.; et al. Sedentary Behavior Research Network (SBRN)-Terminology Consensus Project process and outcome. Int. J. Behav. Nutr. Phys. Act. 2017, 14, 1-17. [CrossRef]

18. Bergman, F.; Wahlström, V.; Stomby, A.; Otten, J.; Lanthén, E.; Renklint, R.; Waling, M.; Sörlin, A.; Boraxbekk, C.-J.; Wennberg, P.; et al. Treadmill workstations in office workers who are overweight or obese: A randomised controlled trial. Lancet Public Health 2018, 2667, 1-13. [CrossRef]

19. Hadgraft, N.T.; Healy, G.N.H.; Owen, N.; Winkler, E.A.H.; Lynch, B.M.; Sethi, P.; Eakin, E.G.; Moodie, M.; Lamontagne, A.D.; Wiesner, G.; et al. Office workers' objectively assessed total and prolonged sitting time: Individual-level correlates and worksite variations. Prev. Med. Rep. 2016, 4, 184-191. [CrossRef]

20. Johansson, E.; Mathiassen, S.E.; Lund Rasmusse, C.; Hallman, D.M. Sitting, standing and moving during work and leisure among male and female office workers of different age: A compositional data analysis. BMC Public Health 2020, 20, 826. [CrossRef]

21. Hadgraft, N.T.; Winkler, E.A.H.; Healy, G.N.; Lynch, B.M.; Neuhaus, M.; Eakin, E.G.; Dunstan, D.W.; Owen, N.; Fjeldsoe, B.S. Intervening to reduce workplace sitting: Mediating role of social-cognitive constructs during a cluster randomised controlled trial. Int. J. Behav. Nutr. Phys. Act. 2017, 14, 1-9. [CrossRef] [PubMed] 
22. Sugiyama, T.; Hadgraft, N.T.; Healy, G.N.; Owen, N.; Dunstan, D.W. Perceived Availability of Office Shared Spaces and Workplace Sitting: Moderation by Organizational Norms and Behavioral Autonomy. Environ. Behav. 2018. [CrossRef]

23. Chu, A.H.Y.; Ng, S.H.X.; Tan, C.S.; Win, A.M.; Koh, D.; Müller-Riemenschneider, F. A systematic review and meta-analysis of workplace intervention strategies to reduce sedentary time in white-collar workers. Obes. Rev. 2016, 17, 467-481. [CrossRef] [PubMed]

24. Lahtinen, M.; Ruohomäki, V.; Haapakangas, A.; Reijula, K. Developmental needs of workplace design practices. Intell. Build. Int. 2015, 7, 198-214. [CrossRef]

25. Wohlers, C.; Hertel, G. Choosing where to work at work-towards a theoretical model of benefits and risks of activity-based flexible offices. Ergonomics 2017, 60, 467-486. [CrossRef] [PubMed]

26. Engelen, L.; Chau, J.; Young, S.; Mackey, M.; Jeyapalan, D.; Bauman, A. Is activity-based working impacting health, work performance and perceptions? A systematic review. Build. Res. Inf. 2019, 47, 468-479. [CrossRef]

27. Wahlström, V.; Bergman, F.; Öhberg, F.; Eskilsson, T.; Olsson, T.; Järvholm, L.S. Effects of a multicomponent physical activity promoting program on sedentary behavior, physical activity and body measures: A longitudinal study in different office types. Scand. J. Work. Environ. Health 2019, 45, 493-504. [CrossRef]

28. Sullivan, M.; Karlsson, J.; Ware, J.E. The Swedish SF-36 Health Survey-I. Evaluation of data quality, scaling assumptions, reliability and construct validity across general populations in Sweden. Soc. Sci. Med. 1995, 41, 1349-1358. [CrossRef]

29. Wahlström, J.; Hagberg, M.; Toomingas, A.; Wigaeus Tornqvist, E. Perceived muscular tension, job strain, physical exposure, and associations with neck pain among VDU users; a prospective cohort study. Occup. Environ. Med. 2004, 61, 523-528. [CrossRef]

30. Nordin, M.; Åkerstedt, T.; Nordin, S. Psychometric evaluation and normative data for the karolinska sleep questionnaire. Sleep Biol. Rhythms 2013, 11, 216-226. [CrossRef]

31. Ng, N.; Söderman, K.; Norberg, M.; Öhman, A. Increasing physical activity, but persisting social gaps among middle-aged people: Trends in Northern Sweden from 1990 to 2007. Glob. Health Action 2011, 4, 6347. [CrossRef] [PubMed]

32. Ulijaszek, S.J.; Kerr, D.A. Anthropometric measurement error and the assessment of nutritional status. Br. J. Nutr. 1999, 82, 165. [CrossRef] [PubMed]

33. Jahncke, H. Open-plan office noise: The susceptibility and suitability of different cognitive tasks for work in the presence of irrelevant speech. Noise Health 2012, 14, 315-320. [CrossRef] [PubMed]

34. Jahncke, H.; Hongisto, V.; Virjonen, P. Cognitive performance during irrelevant speech: Effects of speech intelligibility and office-task characteristics. Appl. Acoust. 2013. [CrossRef]

35. Nilsson, P.; Bringsén, Å.; Ingemar, A.H.; Eilertsson, G. Development and quality analysis of the Work Experience Measurement Scale (WEMS). Work 2010, 35, 49-62. [CrossRef]

36. Bringsén, Å.; Andersson, H.I.; Ejlertsson, G. Development and quality analysis of the Salutogenic Health Indicator Scale (SHIS). Scand. J. Public Health 2009, 37, 13-19. [CrossRef]

37. Pejtersen, J.H.; Kristensen, T.S.; Borg, V.; Bjorner, J.B. The second version of the Copenhagen Psychosocial Questionnaire. Scand. J. Public Health 2010, 38, 8-24. [CrossRef]

38. Lyden, K.; Kozey Keadle, S.L.; Staudenmayer, J.W.; Freedson, P.S. Validity of two wearable monitors to estimate breaks from sedentary time. Med. Sci. Sports Exerc. 2012, 44, 2243-2252. [CrossRef]

39. Grant, P.M.; Ryan, C.G.; Tigbe, W.W.; Granat, M.H. The validation of a novel activity monitor in the measurement of posture and motion during everyday activities. Br. J. Sports Med. 2006, 40, 992-997. [CrossRef]

40. Edwardson, C.L.; Winkler, E.A.H.; Bodicoat, D.H.; Yates, T.; Davies, M.J.; Dunstan, D.W.; Healy, G.N. Considerations when using the activPAL monitor in field-based research with adult populations. J. Sport Health Sci. 2017, 6, 162-178. [CrossRef]

41. Pages, J. Factorial Analysis of Mixed Data. In Multiple Factor Analysis by Example Using R, 1st ed.; Chambers, J.M., Hothorn, T., Temple-Lang, D., Wickham, H., Eds.; CRC Press: Boca Raton, FL, USA, 2014; pp. 67-74.

42. Flint, S.W.; Crank, H.; Tew, G.; Till, S. "it's not an Obvious Issue, is It?” Office-Based Employees' Perceptions of Prolonged Sitting at Work: A Qualitative Study. J. Occup. Environ. Med. 2017, 59, 1161-1165. [CrossRef] [PubMed] 
43. Nooijen, C.F.J.; Kallings, L.V.; Blom, V.; Ekblom, Ö.; Forsell, Y.; Ekblom, M.M. Common perceived barriers and facilitators for reducing sedentary behaviour among office workers. Int. J. Environ. Res. Public Health 2018, 15, 792. [CrossRef] [PubMed]

44. Sudholz, B.; Salmon, J.; Mussap, A.J. Workplace health beliefs concerning physical activity and sedentary behaviour. Occup. Med. (Chic. Ill.) 2018, 68, 631-634. [CrossRef] [PubMed]

45. Thorp, A.A.; Kingwell, B.A.; Owen, N.; Dunstan, D.W. Breaking up workplace sitting time with intermittent standing bouts improves fatigue and musculoskeletal discomfort in overweight/obese office workers. Occup. Environ. Med. 2014, 71, 765-771. [CrossRef]

46. Danquah, I.H.; Kloster, S.; Holtermann, A.; Aadahl, M.; Tolstrup, J.S. Effects on musculoskeletal pain from “Take a stand!"-A cluster-randomized controlled trial reducing sitting time among office workers. Scand. J. Work. Environ. Health 2017, 43, 350-357. [CrossRef]

47. Edwardson, C.L.; Yates, T.; Biddle, S.J.H.; Davies, M.J.; Dunstan, D.W.; Esliger, D.W.; Gray, L.J.; Jackson, B.; O'Connell, S.E.; Waheed, G.; et al. Effectiveness of the stand more at (SMArT) work intervention: Cluster randomised controlled trial. BMJ 2018, 363. [CrossRef]

48. Owen, N.; Sugiyama, T.; Eakin, E.E.; Gardiner, P.A.; Tremblay, M.S.; Sallis, J.F. Adults' sedentary behavior: Determinants and interventions. Am. J. Prev. Med. 2011, 41, 189-196. [CrossRef]

49. Wahlström, V.; Fjellman-Wiklund, A.; Harder, M.; Järvholm, L.S.; Eskilsson, T. Implementing a physical activity promoting program in a flex-office: A process evaluation with a mixed methods design. Int. J. Environ. Res. Public Health 2020, 17, 23. [CrossRef]

Publisher's Note: MDPI stays neutral with regard to jurisdictional claims in published maps and institutional affiliations.

(C) 2020 by the authors. Licensee MDPI, Basel, Switzerland. This article is an open access article distributed under the terms and conditions of the Creative Commons Attribution (CC BY) license (http://creativecommons.org/licenses/by/4.0/). 